Author's Version

Annals of Science, published online 6 September 2020

DOI: $10.1080 / 00033790.2020 .1811377$

\title{
Linear Programming from Fibonacci to Farkas
}

\author{
Norman Biggs
}

\begin{abstract}
At the beginning of the 13th century Fibonacci described the rules for making mixtures of all kinds, using the notation and methods of the Hindu-Arabic system of arithmetic. His work was repeated in the early printed books of arithmetic, many of which contained chapters on 'alligation', as the subject became known. But the rules were expressed in words, so the subject often appeared difficult, and occasionally mysterious. Some clarity began to appear when Thomas Harriot introduced a modern form of algebraic notation around 1600, and he was almost certainly the first to express the basic rule of alligation in algebraic terms. Thus a link was forged with the work on Diophantine problems that occupied mathematicians like John Pell and John Kersey in the 17th century. Joseph Fourier's work on mechanics led him to suggest a procedure for handling linear inequalities based on a combination of logic and algebra; he also introduced the idea of describing the set of feasible solutions geometrically. In 1898, inspired by Fourier's work, Gyula Farkas proved what we now regard as the fundamental theorem about systems of linear inequalities. This topic eventually found many applications, and it became known as Linear Programming. The theorem of Farkas also plays a significant role in Game Theory.
\end{abstract}

\section{Introduction}

In 1279 Edward I, king of England, instituted a major reform of his coinage, with the aim of controlling more strictly the weight and fineness (purity) of the coins produced at the mints. A few years later one of Edward's mint officers wrote the Tractatus Nova Moneta, explaining the problems involved in great detail. One of these problems was the following: ${ }^{1}$

Suppose I have to alloy the money to be ninepence fine and have bullion or silver elevenpence fine and fourpence fine.

[Pono quod debeam alliare monetam ad ixd. de allaio et habeam billionem siue argentum ad xjd. de allaio et ad iiijd. de allaio.]

\footnotetext{
${ }^{1}$ For the background to the Tractatus see Martin Allen, Mints and Money in Medieval England (Cambridge: Cambridge University Press, 2012) and Nicholas Mayhew, 'From Regional to Central Minting', in $A$ New History of the Royal Mint ed. by Christopher Challis (Cambridge: Cambridge University Press, 1992) pp. 81-178. The extract is from the Red Book of the Exchequer, translated by Charles Johnson, The De Moneta of Nicholas Oresme and English Mint Documents (London: Nelson, 1950) 71.
} 
The question is: how to make silver coins of a specific fineness, given that two sorts of silver are available, one better and one worse than the required standard. The standard of 'ninepence fine' meant that 9 parts out of 12 were pure silver. We now measure fineness as a percentage or 'parts per thousand', so that sterling silver is $92,5 \%$ pure, or ' 925 ', but in medieval times the assayers used strange measures that had evolved as part of the mystery of their craft. Here pure silver is reckoned as ' 12 pence fine', so the coins at ' 9 pence fine' are required to be $75 \%$ pure. This is not a standard that was actually used in England, and clearly the writer's intention is to illustrate the need for arithmetical skill in the practice of minting.

The solution is obtained by noting that one of the sources is 2 pence better than required, and other is 5 pence worse, so they should be combined in the proportion of 5 to 2 . Although the principle is clear intuitively, the writer goes on to justify the result by calculating the fineness of the mixture directly, in two different ways.

The present paper builds on the seminal work of Jack Williams, ${ }^{2}$ who described the methods used in the minting of coins, up to 1700 . Here we shall begin by looking more closely at the mathematics underlying the procedures used in the late medieval period. Then we shall describe how, following the work of Thomas Harriot and John Pell in the 17th century, the subject was treated by algebraic methods. Finally, we shall explain how analytical methods were deployed to establish an important mathematical theory, Linear Programming.

We focus initially on the evolution of the methods and notations that were traditionally used to describe the making of mixtures of all kinds. The arithmetical methods described by Fibonacci at the start of the 13th century became widely known in the 15th and 16th centuries, when printed textbooks of arithmetic began to appear. But the subject was presented in the form of rules, which often obscured the underlying principles. Around 1600, Thomas Harriot developed a symbolic form of algebra, very similar to the form we use today, and he was the first to express Fibonacci's arithmetical rules in that way. In the 17th century the work of John Pell, John Kersey, and others, showed how algebraic techniques could provide a clearer understanding of the subject, especially the aspects of 'indeterminacy'. Much later, a similar combination of logic and algebra was discussed by Joseph Fourier, who also introduced the idea of describing the set of feasible solutions geometrically.

In the second half of the 19th century the subject we now know as Linear Algebra began to take shape. In 1873, when Paul Gordan proved a 'Theorem of the Alternative' about the existence of non-negative solutions of a system of linear homogeneous equations, he used determinants in his paper. Twenty-five years later Gyula Farkas, inspired by Fourier's work, proved a significant extension of Gordan's result, about non-homogeneous equations. In the twentieth century Linear Algebra found many new applications, notably as a tool for solving complex problems of organisation and planning. Thus there arose the subject of Operations Research. One of its main tools was Linear Programming, where it turned out that the 'Farkas

\footnotetext{
2 Jack Williams, 'Mathematics and the Alloying of Coinage 1202-1700' Annals of Science 52 (1995), 212-234, 235-263.
} 
Lemma' plays a fundamental role. In fact, the underlying mathematical principle also played a central role in the development of Game Theory and other areas of Mathematical Economics.

\section{Fibonacci: arithmetic, alloying, and birds}

The arithmetic that appeared in the Tractatus Nova Moneta was not new. We do not know when it was first used in England, but it was surely familiar to the experts who were imported to help manage the English coinage in the 13th century, several of them from Italy. ${ }^{3}$ One of them, Orlandino da Poggio, was appointed joint Warden of the Exchange and Mint in 1279 , as a representative of the king's bankers, the Riccardi of Lucca. The Riccardi were entrusted with running the Exchange, where silver of all levels of fineness was received, valued, and exchanged for current coin, an operation that required considerable skill in arithmetic. Another Italian, Boniface Galgani from Florence, was assayer, buyer, and weigher from 1279 to 1281 . Almost certainly such men would have been familiar with the Liber Abbaci of Leonardo of Pisa, often known as Fibonacci. ${ }^{4}$ The widespread circulation of this work was truly ground-breaking: it signalled the transition from the ancient methods of calculating with counters, to pen-reckoning with the Hindu-Arabic numerals and algorithms. Fibonacci had learned his craft on his travels in the Islamic lands surrounding the Mediterranean Sea where, significantly, gold and silver coins were common at that time. Indeed, the application of arithmetical methods to coinage may well go further back, to the mints of Greece, Rome, Byzantium and India. For example, the Indian document known as the Bakshali Manuscript contains several problems about combining gold coins of different finenesses. $^{5}$

Fibonacci's manuscripts contained a great deal of commercial arithmetic, as well as some more famous arithmetical puzzles. In Section 6 of Chapter 11 (On the Alloying of Money) he considered the problem of producing silver coins with fineness $5 \frac{1}{8}$ ounces per pound, given two sorts of bullion, one at $4 \frac{1}{2}$ ounces per pound and one at $6 \frac{1}{4}$ ounces per pound. (Here the fineness is measured in an Italian style, by the number of ounces of pure silver in a pound of twelve ounces: so the required standard is about $42.7 \%$.) Fibonacci reduced the problem to whole numbers by taking the unit of fineness to be one-eighth of an ounce, so that one sort is better by 9 units and the other is worse by 5 units. It follows that they should be mixed in the proportion 5 to 9 .

\footnotetext{
${ }^{3}$ For the general background to the Italian bankers in England see Walter Rhodes 'The Italian bankers in England and their loans to Edward I and Edward II', in Historical Essays ed. by T.F. Tout and J.F. Tait (London: Longmans, 1902). For a more numismatic account, see Mavis Mate. 'Monetary Policies in England 1272-1307' British Numismatic Journal 41 (1972) 34-79.

${ }^{4}$ Fibonacci's work first appeared in 1202 and was revised in 1228. The Latin text has been published by B. Boncompagni , Scritti di Leonardo Pisano (Rome: 1857) and there is an English translation by L. Sigler Fibonacci's Liber Abaci (Springer: New York, 2002).

${ }^{5}$ Kim Plofker, 'Mathematics in India' in The Mathematics of Egypt, Mesopotamia, China, India and Islam, ed. by Victor Katz (Princeton: Princeton University Press, 2007) pp.435=437.
} 
Fibonacci also considered problems where more than two kinds of bullion are available. As a simple illustration, he discussed the case where the standard is 5 ounces fine, and there is one better kind of bullion ( 6 ounces fine), and two worse kinds ( 4 and 3 ounces fine). His first solution is to mix the two worse kinds in equal amounts, making a single worse kind, $3 \frac{1}{2}$ ounces fine, and then combine that with the better kind, using the simple rule. This produces a standard mixture in which the proportions of the three constituents are $3: 1: 1$. Significantly, he then observes that there are other ways of achieving the desired result. For example, if the two worse kinds are combined in a different way, say in the proportion $5: 2$, then the resulting mixture is $3 \frac{5}{7}$ ounces fine, and combining that with the better kind using the simple rule produces a mixture in which the proportions of the three constituents are 9:5:2. As we shall see, this remarkable insight into the 'indeterminacy' of the problem would be overlooked in many later accounts, when the problem was presented in terms of codified rules.

The Liber Abbaci is best known for its many delightful arithmetical puzzles, such as the 'Seven Old Men Going to Rome' and the 'Rabbits'. The puzzles mainly occur in Chapter 12, and are preceded by the serious mathematics such as 'the Alloying of Monies', which is in Chapter 11. A particularly striking illustration of the book's true priorities appears towards the end of Chapter 11, where Fibonacci introduces the puzzle of 'The Three Kinds of Birds' and solves it by converting it into a problem of alloying money. Clearly, he was aware that the rules for alloying money were based on mathematical principles that had wider application. In Section 5 we shall discuss another method used by Fibonacci for the 'Birds' problem, which resembles modern algorithmic techniques.

The problem is as follows: thirty birds of three kinds, A, B, C, are bought for thirty pence. Each A costs 3 pence, each B costs 2 pence, and each $\mathrm{C}$ costs half a penny. How many birds of each kind are bought? Fibonacci remarks that this problem is equivalent to making a 'standard' alloy of fineness 1 (since 30 birds are bought for 30 pence), using three kinds of 'bullion', with finenesses 3, 2, and $1 / 2$. Because the numbers of birds are required to be positive integers, he works in multiples of $1 / 2$, so the finenesses of A, B, C are $6,4,1$, and the 'standard' is 2. Now he can use the pairing rule in the usual way. A and $\mathrm{C}$ must be combined in the ratio $1: 4$, since $6-2=4$ and $2-1=1$. Similarly, $B$ and $C$ must be combined in the ratio $1: 2$. In other words, one lot of the AC alloy contains 1 A-bird and 4 C-birds, while one lot of the $\mathrm{BC}$ alloy contains 1 B-bird and 2 C-birds. Both these alloys are 'standard' so they can be combined in any way, and it remains only to work out how AC lots of 5 birds and $\mathrm{BC}$ lots of 3 birds can be combined to make 30 birds in all. There is in fact only one possibility: 3 lots of 5 and 5 lots of 3 , giving the answer $\mathrm{A}=3, \mathrm{~B}=5, \mathrm{C}=22$.

\section{From manuscript to print}

The problems of combination described in the Liber Abbaci and the Tractatus Nova Moneta were not confined to the minting of coins. They occur whenever mixtures are required, for example when wines are blended by vintners and potions are made up by apothecaries. By the 16th century the subject had become known in English as alligation, and it was discussed 
in the printed books on arithmetic that were starting to appear. But, as was the custom, the methods used were presented without any form of justification, although the results could be checked by a direct calculation.

One of the first printed books to discuss the principles of alligation was the Arithmetica of Piero Borgi, a book specifically intended for the mercantile community. ${ }^{6}$

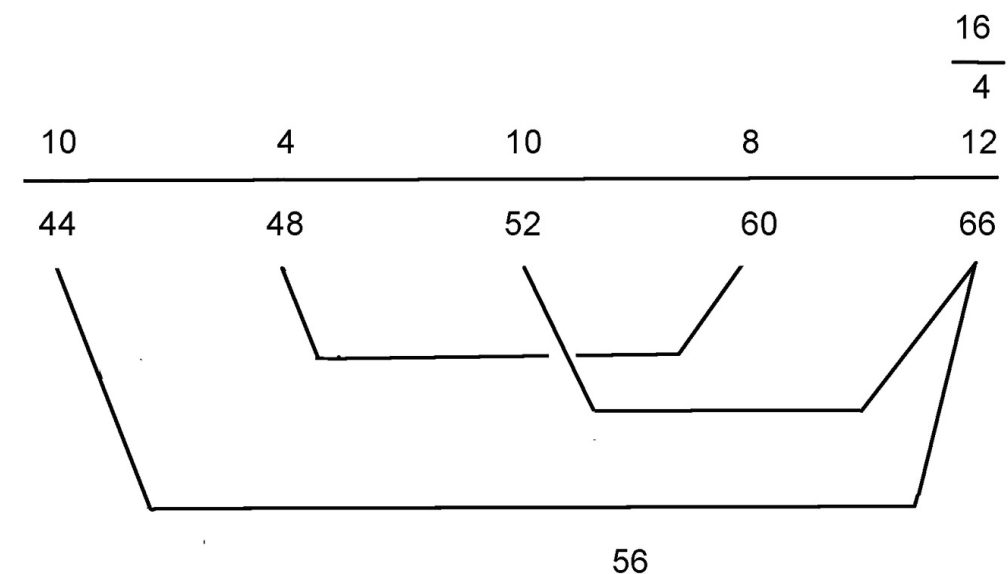

Figure 1. Alligation with five sorts of wine, as presented by Borgi (1488).

Borgi's exposition shows how the principles set out by Fibonacci had become codified by the end of the 15th century. In particular, he deals with the problem of a vintner who has five kinds of wine, with unit-prices 44, 48, 52, 60, and 66, and wishes to produce 50 units priced at 56 (Figure 1). The aim is to find a feasible solution, which could of course be achieved by combining just one pair of the constituents according to the basic rule. However, Borgi follows the usual practice, which was to seek a solution in which all the available constituents are used. This can be achieved by pairing the constituents in several different ways, and then combining the resulting mixtures, all of which have the required property. The idea is clearly illustrated in Borgi's diagram. He takes three pairs, as shown by the links, and mixes them according to the basic rule:

44 and 66 : since $56-44=12$ and $66-56=10$, use 10 units and 12 units;

48 and 60: since $56-48=8$ and $60-56=4$, use 4 units and 8 units;

52 and 66: since $56-52=4$ and $66-56=10$, use 10 units and 4 units.

He adds these three mixtures together, obtaining a mixture totalling 48 units. Since 50 units are required, he then multiplies by $\frac{50}{48}$ to obtain the answer.

Modern vector notation enables us to understand the procedure more generally. Borgi's basic solutions are $(10,0,0,0,12),(0,4,0,8,0)$ and $(0,0,10,0,4)$, which he adds in order to obtain a mixture containing all five ingredients:

$$
(10,0,0,0,4)+(0,4,0,8,0)+(0,0,10,0,4)=(10,4,10,8,16)
$$

${ }^{6}$ Piero Borgi, Qui Comenza la Nobel Opera de Arithmetica (Venice: 1488). Editions of this work were published in 1484 and 1488, preceding the better-known Summa of Pacioli which appeared in 1494. 
Multiplying by $\frac{50}{48}$ gives the answer $\left(10 \frac{5}{12}, 4 \frac{1}{6}, 10 \frac{5}{12}, 8 \frac{1}{3}, 16 \frac{2}{3}\right)$. This simple notation clarifies several aspects of the process, but clarity was not a feature of the descriptions that appeared in many of the textbooks published in the 16th century, when alligation became one of the main topics of practical arithmetic. The Latin word 'alligationis' was used by Widman in 1489, and in 1552 the second edition of Robert Recorde's Grounde of Artes contains one of the first appearances of the word in English. ${ }^{7}$ Unfortunately the rules presented in these books tended to obscure the essential features of the subject, and it would continue to be regarded as 'difficult' for a very long time.

Recorde's book contains an extended account of the subject, and this was the basis of the material that appeared in many subsequent books. Among them was a popular textbook written by the goldsmith Dionis Gray. ${ }^{8}$ Gray's treatment of alligation is similar to Recorde's, but very muddled - and consequently revealing. His first example concerns an apothecary who is required to use four sorts of 'drugges' to make a mixture priced at 40 shillings per ounce. Two sorts (say A and B) are priced at 45 and 42 shillings, and the other two (C and D) are priced at 36 and 32 shillings (Figure 2).

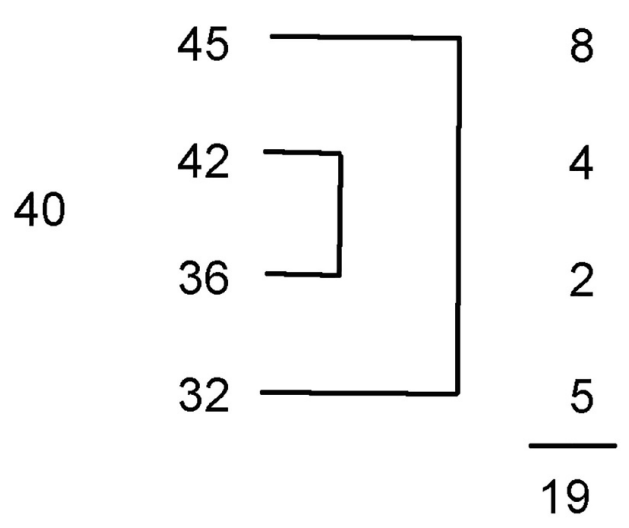

Figure 2: Alligation with four sorts of drugs, as presented by Gray (1577).

As indicated in the diagram, Gray applies the basic pairing rule to A and D, with the result that 8 ounces of A should be mixed with 5 ounces of D. Similarly, 4 ounces of B should be mixed with 2 ounces of $C$. Adding these two mixtures in the usual way produces $8+4+2+5$ $=19$ ounces in total, but the problem asked for 8 ounces, so the quantities must be multiplied by $\frac{8}{19}$.

Gray then remarks that a different solution is obtained if the drugs are paired differently. He means pairing $\mathrm{A}$ with $\mathrm{C}$, and $\mathrm{B}$ with $\mathrm{D}$, but confuses the issue by writing that 'the differences change their places' and referring to a diagram which contains several mistakes.

\footnotetext{
${ }^{7}$ Johannes Widman, Behennd und hupsch Rechnung auf allen Kaufmanschaften (Leipzig: 1489); Robert Recorde, The Grounde of Artes (London: 1552). The OED attributes the word 'alligation' to Richard Taverner, but the context is unclear.

${ }^{8}$ Dionis Gray, The Store-House of Breuitie in Woorks of Arithmetic (London: William Norton and John Harrison, 1577).
} 
In fact, Gray's understanding of alligation was very patchy. He gives several more examples, one of which is hopelessly wrong, and ends with a cryptic comment:

... there are other soundrie orders of prooves, for the commixions of Goldes and Silvers which here I omitte, in respect of severall causes, referring suche as by vocation maie desire knowledge therein to private conference, who maie be satisfied to effecte extraordinaire.

From this comment we may infer that the practitioners of alligation had indeed advanced beyond the simple rules published in the textbooks. Even though the symbolism required to formulate their problems precisely was not yet invented, the mint-men of the 16th century surely had insights that nowadays we should express algebraically. For example, when four constituents A,B,C,D are mixed, it is not necessary to obtain the solution by simply adding the $\mathrm{AD}$ mixture and the $\mathrm{BC}$ mixture in the way that Gray suggests: any combination of the $\mathrm{AD}$ mixture and the $\mathrm{BC}$ mixture will work. Gray's comment suggests that the experts were aware of this possibility, and other methods 'extraordinaire'. The idea had been clearly formulated by Fibonacci, but his analysis had not survived in the printed texts. Gray had described only two solutions to his problem: the first by the pairings $\mathrm{AD}$ and $\mathrm{BC}$, the second by the pairings $\mathrm{AC}$ and BD. In modern notation, the first one leads to $(8,4,2,5)$ by adding $(8,0,0,5)$ and $(0,4,2,0)$, while the second leads to $(4,8,5,2)$ by adding $(4,0,5,0)$ and $(0,8,0,2)$. Why should we not use more general combinations, such as $2(8,0,0,5)+10(0,4,2,0)$, and what then is the significance of the relationship

$$
2(8,0,0,5)+10(0,4,2,0)=4(4,0,5,0)+5(0,8,0,2) ?
$$

In practice the mint-men must have encountered many situations where more complex methods were useful. Their activities were constrained by the fact the quantities

of the various kinds of silver available to them were limited, and choices would have to be made. They did not have the advantages of a succinct notation for describing these problems, but they would have developed heuristic rules for dealing with them. For example, they would probably wish to use up as much low-grade silver as possible, and one way of doing so had been suggested by Fibonacci. All the available silver that was worse than standard could be combined into a single lot, and then combined with a suitable quantity of the better kind. But of course, there might not be enough of the better kind available.

\section{From arithmetic to algebra: the problem of 'indeterminacy'}

Thomas Harriot (1560?-1621) was the finest English mathematician before Newton. He produced over 8000 pages of notes on a wide range of mathematical topics, but none of this work was published in his lifetime. In fact, it was difficult to appreciate the full range of his achievements until his manuscripts were published in 2011. ${ }^{9}$ It is now clear that Harriot had been concerned with several matters relating to the coinage of his time, including alligation.

\footnotetext{
${ }^{9}$ The Harriot papers can be examined online (echo.mpiwg-berlin.mpg.de). The parts relating to alligation and coinage are analysed by Norman Biggs, 'Thomas Harriot on the Coinage of England' Archive for the History of the Exact Sciences 73(4) (2019) 361-383,
} 
Harriot studied the chapter on alligation in the 1585 Arithmetique of Simon Stevin. That work contained several problems set out in the standard form as presented by Recorde and Gray. Harriot worked out the answers to these problems and, significantly, he wrote down the basic pairing rule in algebraic form (Figure 3). Although this would now be regarded as 'elementary algebra', it must be stressed that Harriot's notation was entirely new at that time.

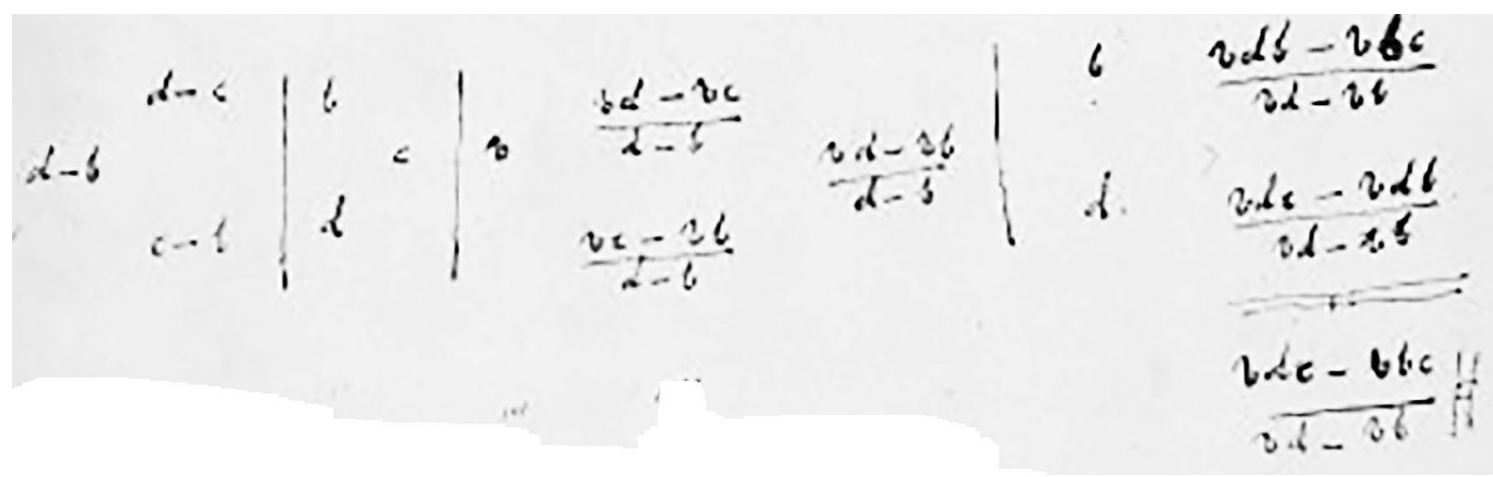

Figure 3: Harriot's algebraic summary of the basic principle of alligation.

(C) British Library Board BL Add MS 6783 f.313v

Harriot's table gives the general form of the quantities that occur when it is required to produce $q$ units of silver with fineness $c$, given that two sorts are available, one with fineness $b$ and one with fineness $d$, where $b<c<d$. According to the usual rule, the sorts must be mixed in the proportion of $d-c$ units of $b$ to $c-b$ units of $d$, making $d-b$ units in all. These quantities are written on the left. In the middle are the quantities needed to produce $q$ units, obtained by multiplying by $q /(d-b)$. On the right is the verification that the fineness of the mixture is correct. Each quantity is multiplied by the respective fineness and divided by $q$; these terms are then added to obtain the fineness of the mixture as the weighted average of the finenesses of the constituents. Since

$$
\frac{q d b-q b c}{q d-q b}+\frac{q d c-q d b}{q d-q b}=\frac{q d c-q b c}{q d-q b}=c,
$$

the result is correct. The absence of any hint of explanation is typical. Harriot's notes were not written for the purpose of instructing others; his only concern was to convince himself. His notes on the pairing rule would have meant little to all but very few of his contemporaries.

Harriot's death in 1621 was followed by efforts to publish his work. Eventually the project fell into the hands of Sir Thomas Aylesbury, a rising star in the royal administration. He had been appointed as a Master of Requests in 1628, and was granted the monopoly of making weights for checking gold coins in 1631. In that year a small volume containing some of Harriot's algebraic work was published, but alligation was not one of the topics covered. Aylesbury became joint Master of the Tower Mint in 1635, and almost certainly he was aware that Harriot's unpublished papers contained material relevant to coinage, in particular alligation, or 'the commixture of monies' as it was known to the mint-men. Aylesbury had become acquainted with John Pell, a rising star of the 
mathematical kind, and it appears that he considered asking Pell to help with further work on the publication of Harriot's papers, but nothing came of it. ${ }^{10}$

Nevertheless, Pell's mathematical interests did extend to some topics relevant to our story. His surviving manuscripts are in an even more chaotic state than Harriot's, but among them some relevant material has been found. He made notes on the chapter on Alligation in the Arithmetica of Gerhard de Neufville. ${ }^{11}$ In that book there is a long discussion of a problem with six kinds of wine, three better and three worse than the required standard, so there are nine possible pairings in all. Neufville finds three solutions using three pairs in different ways, as well as one solution using five pairs and one using eight pairs. In all cases the result is obtained by simply adding the basic mixtures, but it is a good illustration of the fact that many different solutions are possible.

Such 'indeterminacy' also occurs in another area of mathematics which attracted Pell's interest, the study of Diophantine equations. It had become very fashionable, following the re-discovery of the works of Diophantus in the 16th century, and the publication of a commentary on them by Bachet in 1621. A feature of Pell's work on the subject was the use of symbolic algebra in the style of Harriot. On 1 March 1645 he gave Sir Charles Cavendish some notes which included the following problem. ${ }^{12}$ Find positive numbers $a, b, c$ such that

$$
5 a+3 b-2 c=24, \quad \text { and } \quad-2 a+4 b+3 c=51 .
$$

The problem is 'indeterminate' because there are only two equations for three unknowns. However, as Pell observed, the condition that $a, b$ and $c$ must be positive means that the range of possibilities is restricted. He knew how to eliminate variables from systems of simultaneous linear equations, and he saw how to apply the method in this case. ${ }^{13}$ Eliminating $c$ results in the equation $11 a+17 b=174$, which implies that $a$ must be less than $\frac{174}{11}=15 \frac{9}{11}$. (Similarly, $b$ must be less than $10 \frac{4}{17}$.) Pell allowed fractional solutions, of which there are infinitely many, but if the solutions are required to be whole numbers then $a$ must be one of the numbers $1,2,3, \ldots, 15$, and it turns out that there is a unique solution $a=5, b=7, c=11$.

Sir Charles Cavendish, the recipient of the notes on the Diophantine problem, carried on an extensive correspondence with Pell in the years 1641 to 1651. For most of that time England was in the throes of a civil war, and both men were living abroad. The publication of their letters by Malcolm and Stedall has thrown more light on Pell's interest in

\footnotetext{
${ }^{10}$ See note 30/4/9B-18A in the online edition of Samuel Hartlib's Ephemerides (www.dhi.ac.uk/hartlib).

${ }^{11}$ Gerhard de Neufville, Theorica et Practica Arithmetica (Bremen: 1624).

${ }^{12}$ The circumstances are described by Noel Malcolm and Jacqueline Stedall, John Pell (1611-1685) and his Correspondence with Sir Charles Cavendish (Oxford: Oxford University Press, 2005) 290-291.

${ }^{13}$ The 'ordinary' method of elimination was rarely mentioned in the early books on algebra (Joseph Grear, 'How ordinary elimination became Gaussian elimination' Historia Mathematica 38 (2011) 163-218. But it was in fact well known. A very clear example from the middle of the 16th century, using old notation. can be found in the Logistica of Jean Borrel. It has been reprinted with an English translation by Jacqueline Stedall, Mathematics Emerging (Oxford: Oxford University Press, 2008) pp. 548-551. Pell's notes for Cavendish contained an example taken from Gosselin's De Arte Magna of 1577, with modernised notation.
} 
indeterminate problems. ${ }^{14}$ In Letter 51 Cavendish mentions Pell's notes on the problem discussed above and asks for more explanation. In Letter 52 he specifically mentions Alligation and asks if Pell knows of a 'goode demonstration' of the rule. In Letter 55 Pell replies:

... you desire good demonstrations of ye rules of Alligation \& Falshoode. But, as I remember, I have heeretofore told you, that neither of them have ever beene taught or confirmed as they ought. And that amongst ye taskes which I have set myselfe, that is one.

This remark indicates that Pell was unaware of Harriot's work on alligation (Figure 3). That would not have been the case had he taken advantage of his contacts with Aylesbury in the 1630s. Furthermore, he was not good at bringing tasks to a conclusion, and no coherent account of his work on indeterminate problems has been found. In fact, none of his algebraic work was published until 1668, and then only in a rather curious way. ${ }^{15}$

Meanwhile, at the Mint the 'commixture of metals' remained a perennial problem. Back in 1635 a tract on the subject had been produced by Walter Warner, probably at the request of the royalist Master of the Mint, Sir Thomas Aylesbury. ${ }^{16}$ By 1650 the royalist regime had collapsed, and Aylesbury was long gone from the Mint. England was under the rule of the parliamentarians, who were greatly concerned about the integrity of the nation's coins. Indeed it was rumoured that Seth Ward, newly appointed as Professor of Astronomy at Oxford, was going to revise Warner's tract. ${ }^{17}$ However, no evidence that Ward actually worked on this project has been found, probably because in 1651 an alternative manual on the same subject appeared in print. This was the Brief and Easie Way by Tables to cast up Silver . . a and Gold, by John Reynolds, the Mint's long-standing authority on the subject. Reynolds presented a neat procedure that enabled an assay-master to produce alloy of standard fineness, using only simple arithmetic and the information contained in his tables. The procedure can be described in algebraic terms, but it seems likely that Reynolds based it on his practical experience of the art of assaying, rather than algebraic theory. ${ }^{18}$

\section{Algebra and logic}

The focus on arithmetical procedures at the Mint, and the elusiveness of Pell's work on algebra, means that we must look elsewhere for clear evidence of the application of symbolic algebra to alligation. One of the most popular 17th-century textbooks of arithmetic was Edmund Wingate's Arithmetick, first published in 1630. It contained a chapter on alligation, similar in style and scope to Recorde's Ground of Artes. In 1650 a

\footnotetext{
${ }^{14}$ See the reference in note 12. The original sources are: Letter 51 (page 459) BL Add MS 4278 f.238-9; Letter 52 (page 461) BL Add MS 4278 f.241; Letter 55 (page 470) BL Add MS 4280 f.117.

${ }^{15}$ The details are described by Jacqueline Stedall, A Discourse Concerning Algebra (Oxford: Oxford University Press, 2002) 135-139.

${ }^{16}$ BL Harleian Ms 6755.

${ }^{17}$ See note 28/1/60B-71A in the online edition of Samuel Hartlib's Ephemerides (www.dhi.ac.uk/hartlib).

${ }^{18}$ For an analysis of Reynolds' method, see Norman Biggs 'John Reynolds of the Mint: A Mathematician in the Service of King and Commonwealth’ Historia Mathematica 48 (2019) 1-28.
} 
second edition appeared, much enlarged and with an Appendix written by Wingate's friend John Kersey. This contained a justification of the rule of alligation by geometry, which Kersey attributed to the second volume of the great Cursus Mathematicus of Pierre Hérigone. ${ }^{19}$ After Wingate's death in 1656 Kersey continued to revise and extend the book, and in 1662 a fourth edition appeared. ${ }^{20}$ Here the geometrical demonstration was followed by an algebraic one. Kersey began by stating (in words) the algebraic identity that we would now write as $x(y-z)=x y-x z$. He then addressed the problem of producing a mixture with fineness $A$ from two constituents with fineness $B$ and $C$, given that $B>A>C$ (Figure 4).

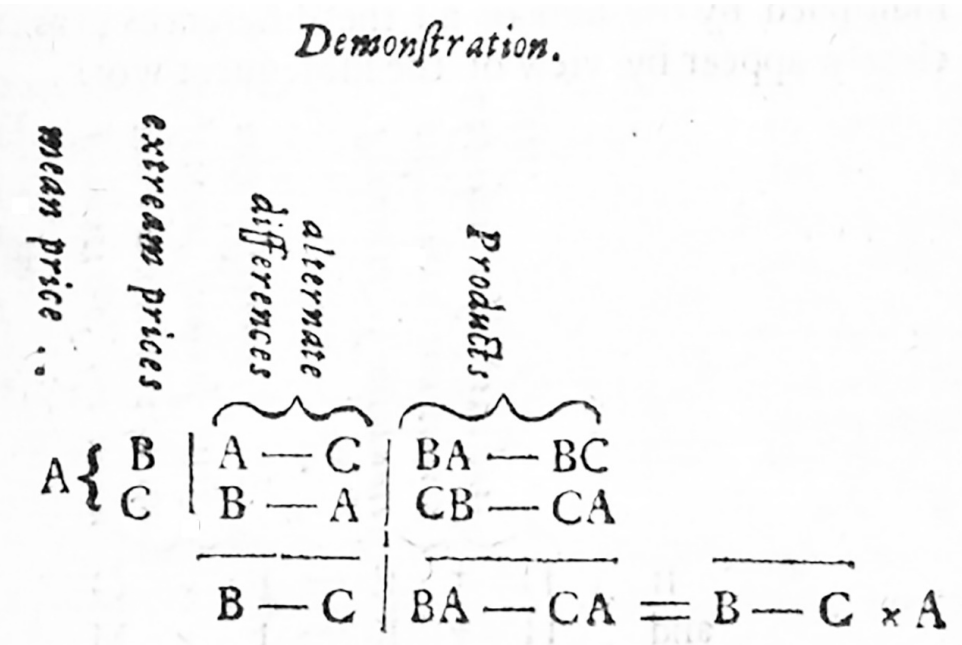

Figure 4. Algebraic demonstration of the rule of alligation (Kersey 1662).

Kersey's working is similar to Harriot's, but clearly explained. He describes the sequence of algebraic operations in words, following the steps that we would now write in symbols:

$$
\begin{aligned}
B \times(A-C)+C \times(B-A) & =(B A-B C)+(C B-C A) \\
& =B A-C A \\
& =(B-C) \times A .
\end{aligned}
$$

In parallel with his work on Wingate's Arithmetick, Kersey was also writing another book, on Algebra. ${ }^{21}$ Chapter 13 is entitled 'Concerning the Reduction of such Arithmetical Questions as are capable of innumerable Answers'. He refers to three propositions from the

\footnotetext{
${ }^{19}$ Pierre Hérigone, Cursus Mathematicus Tomus Secundus (Paris: 1634).

${ }^{20}$ John Kersey, Mr Wingate's Arithmetick (London: 1662).

${ }^{21}$ John Kersey, The Elements of that Mathematical Art commonly called Algebra (London: 1673). John Collins considered this book to be 'much better' than others being offered for publication in the early 1670 s. See Stephen Rigaud, Correspondence of Scientific Men of the Seventeenth Century, Volume 1 (Oxford: Oxford University Press, 1841).
} 
1624 edition of Bachet's Problèmes plaisans et delectables, but remarks that Bachet's methods are 'very tedious and obscure'. Consequently Kersey proposes to use his own methods, which are 'both intelligible and demonstrative'. His Questions 19 and 20 are concerned with alligation, and they do indeed provide a clear exposition of how such problems can be solved by a combination of algebra and logic.

Question 19 is about a vintner who has three sorts of wine, with prices per gallon of 24, 22 , and 18 pence. He wishes to make 60 gallons of wine priced at 20 pence, so the total cost is 1200 pence. Kersey denotes the quantities of the three sorts by $a$, $e$, and $y$, so the basic equations are

$$
a+e+y=60, \quad 24 a+22 e+18 y=1200 .
$$

For practical reasons, all the unknowns are required to be positive. Kersey's first step is to eliminate $a$, which he does by multiplying the first equation by 24 and subtracting the second one. He then eliminates $e$ in a similar way, obtaining (after simplification) the two equations

$$
e+3 y=120, \quad a-2 y=-60 \text {. }
$$

The next step is crucial: further constraints involving fewer variables can be obtained by simple logic. Since $e$ is positive, and $e=120-3 y$, it follows that $y<40$. Since $a$ is positive and $a=2 y-60$, it follows that $y>30$. The conclusion is that $y$ can be any number between 30 and 40, and $a$ and $e$ can then be calculated from the equations stated.

If the numbers are allowed to be fractions there are 'innumerable' answers, but if whole numbers are required then only solutions with $y=31,32, \ldots, 39$ are valid. Kersey notes that only one of these, $y=36$, arises from the traditional pairing method, where the mixtures $(0,2,2)$ and $(2,0,4)$ are added to give $(2,2,6)$, and then multiplied by 6 .

At this point it is appropriate to return to Fibonacci's problem of 'The Three Kinds of Birds'. In the Liber Abbaci the problem was solved by translating it into a problem about alloying money and applying the pairing rule of alligation (Section 2). Fibonacci also discussed variants of the problem in a Letter to Master Theodorus, with different numbers and a different method of solution. ${ }^{22}$ As before, thirty birds of three kinds, A, B, C, were sold for thirty pence. The A-birds cost a penny for three, the B-birds cost a penny for two, and the C-birds cost two pence each. Fibonacci's new method was based on algebraic ideas (although without symbolic notation), and it foreshadowed modern algorithmic techniques for solving linear problems.

Fibonacci's first step was to suppose that all thirty birds were A-birds, in which case the total cost would be only ten pence. He then worked out how the cost would increase if A-birds were exchanged for B-birds or C-birds. Replacing an A-bird by a B-bird increases the cost by one-sixth of a penny, and replacing an A-bird by a C-bird increases the cost by five-thirds of a penny. So he needed to work out how many of these changes would increase the total cost by twenty pence, since thirty pence was spent. In units of one-sixth of a penny, each new $\mathrm{B}$ accounts for one unit, and each new $\mathrm{C}$ accounts for ten units, so the

\footnotetext{
${ }^{22}$ B. Boncompagni, Scritti di Leonardo Pisano II (Rome:1857-62) 247.
} 
number of new B's plus ten times the number of new C's must equal 120. Since both numbers are positive, there is only one possible solution: $10 \mathrm{~B}$ 's and $11 \mathrm{C}$ 's, leaving 9 A's to make up the total of 30 .

In algebraic terms, Fibonacci obtained the equation $b+10 c=120$ by eliminating $a$ (the number of A's) from the two linear equations in $a, b$, and $c$ that represent the given conditions. His last step, applying the condition that the numbers must be positive integers, also anticipates the method of Kersey. Indeed, these ideas recur in the technique we now know as Linear Programming.

Kersey's algebraic method cast new light on the range of the solutions to an alligation problem. In practical terms, it is clear that, since each basic mixture produced by the pairing rule has the required property, these mixtures can be combined in any way. Unfortunately the traditional arithmetical procedure had obscured this obvious fact, because it required the basic mixtures to be added in a specific way.

Slowly, the mist was dispersed. For example, in 1730 the problem was discussed by Alexander Malcolm. ${ }^{23} \mathrm{He}$ observed that the 'Algebraists' had shown how to find an infinite number of different answers. On the other hand, the traditional arithmetical method could provide only a limited number, by using different ways of pairing the constituents. Significantly, he went on to explain that the old method could actually be used to produce infinitely many answers, by increasing or diminishing the amount of the mixture obtained from any pair or pairs. In modern terms, that means using any linear combination of the basic mixtures, not just their sum.

Kersey's procedure is to simplify the system by the elimination of variables and the application of logic to obtain new inequalities. It works well when the number of variables is small, but Kersey made no attempt to describe how it might work more generally, and how the 'infinity' of solutions might be described more precisely. In the 18th century the problem of eliminating variables from a system of equations was commonly taught in courses of algebra, but the corresponding problem for systems of inequalities remained untouched. The next advance in the theory of inequalities came from a new direction.

\section{Fourier and Farkas}

Throughout the 18th century the science of mechanics was gradually transformed by the introduction of algebra and calculus. A recurring theme was the formulation of general 'principles', which could be used to predict the behaviour of mechanical systems. In the great Mécanique Analytique of Joseph Louis Lagrange, published in 1788, the 'principle of virtual velocities' was regarded as one of the fundamental assumptions of statics. In many circumstances this principle can be applied to determine the equilibrium position of a system, by maximizing or minimizing a certain function, subject to given constraints In Lagrange's formulation the constraints were assumed to be equalities, and his method of 'Lagrange multipliers' could be used. This method is relevant to our theme, for two reasons. First, it was the first general framework for dealing with problems of constrained

\footnotetext{
${ }^{23}$ Alexander Malcolm, A New System of Arithmetick (London: J. Osborn and T, Longman, 1730) 568-9.
} 
optimization, and second, the multipliers themselves play a central role in the subsequent development of the subject, as we shall see.

In 1798 Lagrange's compatriot, Jean Baptiste Joseph Fourier, attempted to improve and extend the principle of virtual velocities. In particular, he pointed out that in many practical problems the constraints should be represented by inequalities, rather than equations. Fourier later became famous for his important discoveries about the flow of heat and the representation of functions by infinite series of sines and cosines. This work established him as one of the leading mathematicians of his day, and in 1822 he became secretary of the French Academy of Sciences. That may account for the fact that soon afterwards the Histoire of the Academy contained a long report of two papers he had read to the Academy in November 1823. The subject of the papers was 'le calcul des conditions de inégalités' ${ }^{24}$

The report began by describing a simple experiment, clearly inspired by the problems of analytical statics that the author had discussed in 1798. Suppose a triangular plate is placed in a horizontal position, supported by a pillar at each of its three corners. Each pillar will bear a load of one unit, but no more. A load must be placed on top of the plate, in a position that will not cause it to collapse. If the load exceeds three units a solution is impossible, and if it weighs exactly three units there is a unique solution, the centroid of the triangle. But if the load is (say) two units, then there are many possible solutions. Fourier asserted that the set of feasible solutions can be represented geometrically by a hexagonal region, defined by six inequalities.

A similar report appeared in the Histoire for 1824, and in it Fourier outlined a general method for handling a system of linear inequalities. He considered a system of (strict) linear inequalities involving a finite set of unknowns $x, y, \ldots, u, t$. Every such inequality in which $x$ appears can be written in a form like

$$
x<A+B y+C z+\ldots, \quad \text { or } \quad x>\alpha+\beta y+\gamma z+\ldots .
$$

Comparing a pair of inequalities like these we obtain a new inequality in which $x$ does not appear:

$$
A+B y+C z+\ldots>\alpha+\beta y+\gamma z \ldots
$$

Clearly, the idea is similar to the technique used by Kersey. But the report did not contain any explicit examples, and it did not explain how the method might work in general. In 1826 Fourier wrote a short paper containing a simple example, resembling the mechanical problem described in the first report, but with an explicit algebraic formulation. Perhaps the most significant feature was that the problem was illustrated by a diagram (Figure 5). The combination of geometric intuition with algebraic precision would become a powerful technique for dealing with problems of this kind.

\footnotetext{
${ }^{24}$ Fourier's publications on this topic are conveniently collected in the second volume of his Oeuvres, edited by G. Darboux (Paris: Gauthier-Villars, 1890) pp.317-328. His 1798 Mémoire appears in the same volume.
} 


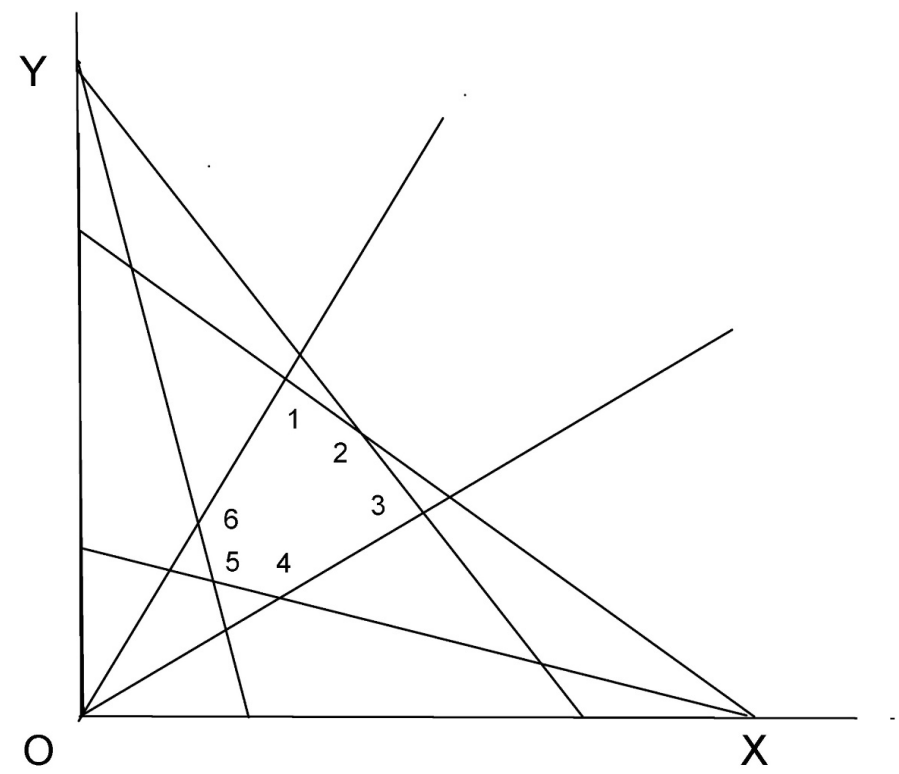

Figure 5. The feasible region for the problem of Fourier (1826).

The problem was to find solutions of the equation $x+y+z=1$ in which the three variables are approximately equal. This means that they must satisfy certain inequalities, which Fourier expressed in the form $y<x(1+r)$, where $r$ is a small number representing the closeness of the approximation required. There are six of these constraints, one for each ordered pair of the variables $x, y, z$. Fourier's method, like Kersey's, began by reducing the number of variables. He substituted $z=1-x-y$, so that only $x$ and $y$ remained, although there are still six constraints. The next step was simple, but significant: he interpreted the constraints geometrically, regarding $(x, y)$ as Cartesian coordinates in a plane. ${ }^{25}$ The form of the constraints means that each of them corresponds to the set of points lying on one side of a straight line, and so the intersection of these regions is the interior of a hexagon, denoted by 123456 in the diagram.

Fourier's method, based on the elimination of a variable by comparing two opposing inequalities, was simple, but there are obvious complications. For example, a reduction in the number of variables may result in an increase in the number of constraints. The publication of the second volume of Fourier's Oeuvres in 1890 may have been responsible for a particularly significant development. Gyula Farkas (1847-1930) was a professor of theoretical physics, and his interest in the principles of mechanics led him to consider the foundations of Fourier's work on systems of inequalities. In 1894, in his first publication

\footnotetext{
${ }^{25}$ In the diagram $O X$ represents the line $y=0$, and $O Y$ represents the line $x=0$. The line $X Y$ (not drawn) represents $x+y=1$ (that is, $z=0$ ) and so all the positive solutions lie inside the triangle $O X Y$.
} 
on the subject, he proposed a theory based on the method of Lagrange multipliers. His theory was incomplete, but a few years later he was able to prove a now-famous theorem. ${ }^{26}$

The theorem establishes a necessary and sufficient condition that the inequality

$$
\text { (Q) } \quad b_{1} u_{1}+b_{2} u_{2}+\cdots+b_{n} u_{n} \geq 0
$$

is a consequence of the $m$ inequalities

$$
\left(Q_{j}\right) \quad a_{1 j} u_{1}+a_{2 j} u_{2}+\cdots+a_{n j} u_{n} \geq 0 \quad(1 \leq j \leq m) .
$$

This means that given any $n$-tuple of real numbers $u_{1}, u_{2}, \ldots, u_{n}$ for which all the inequalities $\left(Q_{j}\right)$ are true, the inequality $(Q)$ is also true. The necessary and sufficient condition is the existence of non-negative real numbers $v_{1}, v_{2}, \ldots, v_{m}$ such that the coefficients $\left(a_{i j}\right)$ and $\left(b_{i}\right)$ satisfy the equations

$$
b_{i}=v_{1} a_{i 1}+v_{2} a_{i 2}+\cdots+v_{m} a_{i m}(1 \leq i \leq n) \text {. }
$$

The numbers $v_{1}, v_{2}, \ldots, v_{m}$ are analogous to Lagrange multipliers, as Farkas had suggested in his earlier paper. It is easy to show that the condition is sufficient; the difficulty lies in proving that it is necessary.

\section{Linear Programming}

The proof published by Farkas in 1898 was elementary (but complicated) and written in a language (Hungarian) which few mathematicians could read easily. It was repeated in a longer paper written in German and published a few years later, which helped to make the result more widely known, although it was not regarded as part of mainstream mathematics at that time. So how did it become famous?

The theory of linear inequalities arose in several contexts in the early 20th century, and some of the resulting publications contained equivalent versions of the 'Farkas Lemma'. In 1936 many of these versions were collected and systematized by Theodore Motzkin in his doctoral thesis. ${ }^{27}$ However, the thesis was purely theoretical, and it remained almost unknown until the 1950s, when Albert Tucker, David Gale and others recognised that it was a fundamental contribution to an emerging field of Applied Mathematics. It had gradually become clear that large-scale problems of organisation and planning could be formulated in mathematical terms, and thence arose the discipline known as Operations Research (sometimes Operational Research, abbreviated to OR).

\footnotetext{
${ }^{26}$ Gyula Farkas, 'Applications of the Mechanical Principle of Fourier' and 'Algebraic Basis of the Mechanical Principle of Fourier' [Hungarian] Mathematikai es Termeszettudomanyi Ertesito 12 (1894) 457-472 and 16 (1898) 361-364.

${ }^{27}$ Theodore Motzkin, Beitrage zur Theorie der Lineaaren Ungleichungen (Doctoral thesis, Basel/Jerusalem, 1936). Fourier's method of eliminating variables from a system of linear inequalities is now known as 'Fourier-Motzkin Elimination'; see Paul Williams, 'Fourier's method of Linear Programming' American Mathematical Monthly 33(9) (1986) 681-675.
} 
Several areas of mathematics were associated with this development: for example there were significant advances in Combinatorial Optimization, as described by Schrijver. ${ }^{28}$

One of the founders of OR was George Dantzig. During the Second World War he had worked on various operational problems in an ad hoc manner, usually in situations where there were many variables and any solution was acceptable. Subsequently he tried to deal with such problems in a more structured way, encouraged by the achievements of Wassily Leontief, who had obtained significant results on equilibrium in linear models of an economy in which there are many inter-dependent industries. Dantzig realized that the next step was to set up a model in which a linear function was optimized, subject to a set of linear constraints, and by 1947 he had begun to develop a general method for solving such problems. This topic eventually became known as Linear Programming (LP), and Dantzig's method became the 'simplex algorithm'.

Although Dantzig's method seemed to work well on small examples, for real problems involving a large number of variables it required a significant amount of calculation - and the time was ripe, because electronic computers were just starting to become available. On 3 October 1947 Dantzig visited John von Neumann, who was playing a leading part in the computer revolution. Dantzig began by describing the practical importance of his work, but von Neumann asked him to focus on the mathematics. Immediately, von Neumann spotted the link between Linear Programming and the Theory of Games, a subject he had been working on for over twenty years. He gave an impromptu lecture on the mathematical foundations and, as Dantzig reports, 'Thus I learned about Farkas' Lemma, and about Duality'. ${ }^{29}$

The version of the 'Lemma' proved by Farkas in 1898, as described in the previous section, asserts the equivalence of two statements. In modern notation, the given information consists of a matrix $A=\left(a_{i j}\right)$ and a column vector $b=\left(b_{i}\right)$, where $A$ has $n$ rows and $m$ columns and $b$ has $n$ rows. The conclusion is expressed in terms of column vectors $u$ and $v$ with $n$ and $m$ rows respectively. ${ }^{30}$ The equivalent statements are:

(I) for all $u, u^{T} A \geq 0$ implies that $u^{T} b \geq 0$;

(II) there exists $v$ such that $A v=b$ and $v \geq 0$.

The first statement is logically equivalent to

(Ia) there does not exist $u$ such that $u^{T} A \geq 0$ and $u^{T} b<0$.

Another logical twist allows us to state Farkas's result in a particularly neat way. Interchanging the order of the statements (Ia) and (II) we have a 'Theorem of the Alternative': the assertion that exactly one of the following holds:

\footnotetext{
${ }^{28}$ Alexander Schrijver, 'On the History of Combinatorial Optimisation (till 1960)' in Handbooks in Operations Research: Discrete Optimisation, ed. by K. Ardaal et al. (Amsterdam: North-Holland, 2005).

${ }^{29}$ George Dantzig, 'Linear Programming' Operations Research 50(1) (2002) 42-47. Von Neumann had also worked on the Leontief model, where the prices of commodities occur naturally as the 'dual' variables. Essentially the same idea is now regarded as fundamental in financial mathematics, where the 'no free lunch' principle is equivalent to the existence of a consistent system of prices: this is a direct consequence of the Farkas Lemma.

${ }^{30} \mathrm{We}$ denote the transpose of $u$ by $u^{T}$ and follow the usual conventions about inequalities between vectors.
} 
there exists $v$ such that $A v=b$ and $v \geq 0$; there exists $u$ such that $u^{T} A \geq 0$ and $u^{T} b<0$.

Farkas's method was based on the ideas of Fourier, and he appears to have been unaware that a simpler Theorem of the Alternative had been proved by Paul Gordan in 1873, using the methods of classical algebra, including determinants (but not matrices).

With modern terminology the crucial importance of the Lemma in the theory of Linear Programming can now be described. Consider two linear programs, the 'Primal'

$$
\max \left\{c^{T} x \mid A x \leq b \text { and } x \geq 0\right\}
$$

and its 'Dual'

$$
\min \left\{b^{T} y \mid A^{T} y \geq c \text { and } y \geq 0\right\} .
$$

It follows directly from the definitions that a solution for the Primal program cannot exceed a solution for the Dual. The key result is that the two values are the same. This is proved by applying the Farkas Lemma (or some equivalent result), as von Neumann suggested to Dantzig in October 1947. Essentially the same argument could be used to prove von Neumann's Minimax Theorem, which guarantees the existence of equilibrium in two-person zero-sum games.

\section{Alligation reconsidered}

Returning to the late medieval texts, the modern theory can throw some light on the rather obscure methods and rules that were then in use.

In modern notation, the basic problem of alligation is as follows. A number $n$ of varieties of a commodity, with 'grades' (prices or finenesses) $g_{1}, g_{2}, \ldots, g_{n}$ are given, and it is required to determine proportions $p_{1}, p_{2}, \ldots, p_{n}$ that will make a mixture with a standard grade $s$. The equations to be solved are

$$
p_{1}+p_{2}+\ldots+p_{n}=1, \quad g_{1} p_{1}+g_{2} p_{2}+\ldots+g_{n} p_{n}=s,
$$

with the proviso that $p_{1}, p_{2}, \ldots, p_{n}$ must all be non-negative. Let

$$
A=\left[\begin{array}{cccc}
1 & 1 & \ldots & 1 \\
g_{1} & g_{2} & \ldots & g_{n}
\end{array}\right], \quad b=\left[\begin{array}{l}
1 \\
s
\end{array}\right], \quad p^{T}=\left[\begin{array}{llll}
p_{1} & p_{2} & \ldots & p_{n}
\end{array}\right],
$$

so that the problem is to find a solution of $A p=b$ with $p \geq 0$. The Lemma of Farkas asserts that this is possible if and only if, for all $q$, the $n$ inequalities $q^{T} A \geq 0$ imply that $q^{T} b \geq 0$. If we write $q^{T}$ as $[y-x]$ then the first of the $n$ inequalities is $y-g_{1} x \geq 0$, which is represented by the set of points $(x, y)$ lying on or above the line $y=g_{1} x$. Suppose, without loss of generality, that $g_{1}$ is the largest grade and $g_{n}$ the smallest. Then the points $(x, y)$ that satisfy all the $n$ inequalities comprise the area shaded in Figure 6 . The region defined by the inequality $q^{T} b \geq 0$ comprises the points lying on or above the line $y=s x$, and the required conclusion follows if and only if $g_{1} \geq s \geq g_{n}$. Thus Farkas tells us that the alligation problem has a solution if and only if the standard grade $s$ lies between the largest and smallest grades available. 

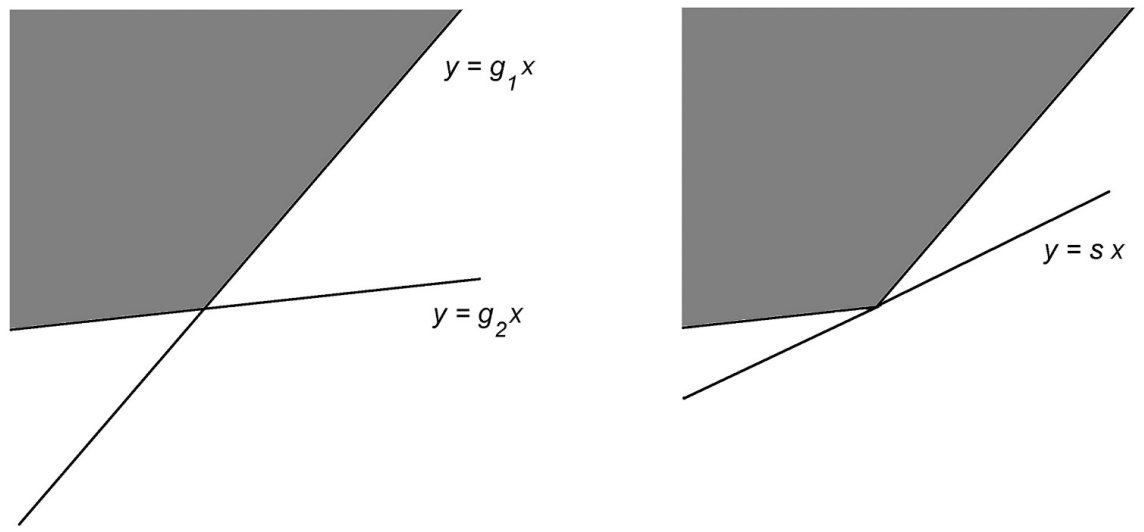

Figure 6. The Farkas Lemma, as applied to alligation.

It is unlikely that the medieval arithmeticians would have been impressed by this application of modern algebra. A deeper insight, which was not available to them, concerns the 'indeterminacy' of the problem. Here it is convenient to replace the proportions by quantities $w_{1}, w_{2}, \ldots, w_{n}$, so that there is one fundamental equation

$$
\left(g_{1}-s\right) w_{1}+\left(g_{2}-s\right) w_{2}+\ldots+\left(g_{n}-s\right) w_{n}=0,
$$

and the solutions form a vector space $W$ with dimension $n-1$. For us, this statement clearly defines the extent of the indeterminacy, but the early practitioners did not have the convenient framework of modern Linear Algebra. However, they did know that many solutions could be produced by the pairing method. Recall that their method was to split the constituents into those with better grades, $g_{1}, \ldots, g_{r}$, and those with worse grades $g_{r+1}, \ldots, g_{n}$, and mix $s-g_{j}$ units of a better grade $g_{i}$ with $g_{i}-s$ units of a worse one $g_{j}$. This produces the mixture we should write as

$$
w^{[i j]}=\left(0, \ldots, 0, s-g_{j}, 0, \ldots, 0, g_{i}-s, 0, \ldots, 0\right) .
$$

Assuming that $0<r<n$, the vector space $W$ contains $r(n-r)$ solutions of this form, and since the dimension of $W$ is $n-1$, one might expect that they span $W$. Indeed, a basis for $W$ can be constructed in the following way: choose one better-worse pair, say $i=1$ and $j=n$, and take the solutions

$$
w^{[1 k]} \quad(r+1 \leq k \leq n), \quad w^{[l n]} \quad(2 \leq l \leq r) .
$$

It is fitting to conclude by repeating that the idea of taking arbitrary linear combinations of basic solutions goes right back to Fibonacci, although it had been lost in the age of the early printed texts on arithmetic. Recall (Section 2) that he discussed a problem with three kinds of silver, one better than standard and two worse. His first solution was to combine equal amounts of the two worse kinds, and then combine the resulting mixture with the better kind according to the simple pairing rule of alligation. But he also observed that the two worse kinds could be combined in any proportion $\alpha: \beta$ before applying the pairing rule. In fact this general method is equivalent to pairing the better kind separately with each of the worse kinds, and then combining these mixtures in the proportion $\alpha: \beta$. This result is easy to check with the algebraic notation outlined above, but obviously it was not so clear in the mysterious world of medieval arithmetic. 


\section{Conclusion}

The story told here is an illustration of how Mathematics has changed during a period of nearly 800 years. Although that seems to be a long time, it is in fact quite short in the context of human development. The story began with an intuitive principle, the pairing rule of alligation, which could be implemented easily using the algorithms of Hindu-Arabic arithmetic, relatively new in Europe at that time. For several centuries the routine aspects of the arithmetic overshadowed the underlying principle, and a deeper understanding of the topic did not begin to appear until the methods of symbolic algebra became available. An input from a quite different area (mechanics) led to the deployment of logical and geometrical ideas, and eventually to the formulation of a fundamental theorem. ${ }^{31}$

This is an example of a general pattern of evolution, which occurs in many branches of Mathematics. The unusual feature here is the economic context: a simple procedure that was widely used in medieval commerce has, in recent times, grown into one of the major tools of modern economic activity.

\section{Acknowledgements}

I am grateful to Paul Williams for advice on Linear Programming and Fourier-Motzkin Elimination, and Philip Beeley for advice on the literature of the seventeenth century.

\section{Disclosure Statement}

No potential conflict of interest was reported by the author.

\footnotetext{
${ }^{31}$ The Farkas Lemma is now often regarded as a corollary of a more general principle, the Separating Hyperplane Theorem for convex sets, but that is another story.
} 